\title{
Comparative proteome analysis of alkaliphilic Bacillus sp. N16-5 grown on different carbon sources
}

\author{
LI Gang ${ }^{1,2}$, SONG YaJian ${ }^{1,2}$, XUE YanFen ${ }^{1}$, RAO Lang ${ }^{1,2}$, ZHOU Chen ${ }^{1,2}$, \\ WANG QuanHui ${ }^{3} \&$ MA YanHe ${ }^{1 *}$ \\ ${ }^{1}$ State Key Laboratory of Microbial Resources, Institute of Microbiology, Chinese Academy of Sciences, Beijing 100101, China; \\ ${ }^{2}$ Graduate University of Chinese Academy of Sciences, Beijing 100049, China; \\ ${ }^{3}$ Beijing Proteomics Institute, Beijing 101318, China
}

Received March 24, 2010; accepted April 26, 2010

\begin{abstract}
To determine the impact of carbohydrates on the metabolic pathway in alkaliphiles, proteomes were obtained from cultures containing different carbohydrates and were resolved on two-dimensional gel electrophoresis (2-DE). The proteomes were compared to determine differentially expressed proteins. A novel alkaliphilic bacterium (alkaliphilic Bacillus sp. N16-5 isolated from Wudunur Soda Lake, China) was isolated in media with five different carbon sources (glucose, mannose, galactose, arabinose, and xylose). Comparative proteome analysis identified 61 differentially expressed proteins, which were mainly involved in carbohydrate metabolism, amino acid transport, and metabolism, as well as energy production and conversion. The comparison was based on the draft genome sequence of strain N16-5. The abundance of enzymes involved in central metabolism was significantly changed when exposed to various carbohydrates. Notably, catabolite control protein A (CcpA) was up-regulated under all carbon sources compared with glucose. In addition, pentose exhibited a stronger effect than hexose in CcpA-mediated carbon catabolite repression. These results provided a fundamental understanding of carbohydrate metabolism in alkaliphiles.
\end{abstract}

Bacillus sp. N16-5, alkaliphile, cytoplasmic protein, 2-DE

Citation: $\quad$ Li G, Song Y J, Xue Y F, et al. Comparative proteome analysis of alkaliphilic Bacillus sp. N16-5 grown on different carbon sources. Sci China Life Sci, 2011, 54: 90-100, doi: 10.1007/s11427-010-4106-1

Alkaliphiles, an important physiological group of microorganisms, are microorganisms that grow optimally or very well at $\mathrm{pH}$ levels $>9$, and often between 10 and 12. However, alkaliphiles do not grow, or grow slowly, at a nearneutral $\mathrm{pH}$ value of 6.5 [1]. Because alkaliphiles can survive in alkaline environments, they likely contain potentially valuable functional genes and proteins that are not yet explored. Over the past two decades, studies focusing on alkaliphiles have focused on two aspects: (i) adaptation mechanisms of alkaliphiles in an alkaline environment [2-4], and (ii) cloning, expression, and characterization of alkaliphilic

*Corresponding author (email: mayanhe@im.ac.cn) proteins that are stable under alkaline conditions. Enzymes produced by alkaliphiles, such as alkaline protease, alkaline amylase, alkaline pectinase, and alkaline cellulase, have been used as novel biocatalysts on an industrial scale [5-14], because these extremozymes are catalytically faster, more specific, and environmentally friendly.

Bacteria use a variety of substances as nutritional sources of carbon and nitrogen. When grown in an abundance of nutrients, bacteria prefer to utilize the most favorable nutrient source that allows for maximal growth rates. However, under natural conditions, bacteria often encounter nutrient starvation. The ability to rapidly adapt to altered environmental conditions is essential for cell survival, and complex 
regulatory networks are required to allow such adaptations [15].

2-DE analysis of $\mathrm{pH}$-dependent proteins in Bacillus pseudofirmus $\mathrm{OF} 4$, an extremely alkaliphilic bacterium, has been reported [16]. Although a limited number of proteins have been identified, a novel surface layer protein exhibited a role in alkaliphilicity. A previous study [17] focused on the use of a variety of gel-based and gel-free proteomic techniques to elucidate regulation of metabolic pathways (e.g., glycolysis and TCA cycle) in a variety of Bacillus species under changing environment and physiological conditions (stress and starvation). Proteomic signatures were identified, which were correlated with specific physiological states of Bacillus. Under natural conditions, nutrients are present in extremely dilute concentrations, are inaccessible due to water paucity, or are only transiently available. Moreover, the quality of the available nutrients is highly variable. As a result, bacteria have evolved sophisticated adaptation systems to take advantage of the wide range of sources of essential elements, such as carbon, nitrogen, phosphorus, and sulfur [18]. Many studies have reported that the presence of preferred carbon sources prevents expression, as well as activity, of catabolic systems that enable the use of secondary substrates, which is referred to as carbon catabolite repression (CCR). In the firmicute Bacillus subtilis model [19], the pleiotropic transcriptional factor CcpA (catabolite control protein A) is the major factor. Acetate kinase (ackA) is responsible for regulation of the pta-ack pathway (acetyl-CoA-to-acetate) for acetate excretion, which results in synthesis of one ATP molecule [20]. This step in the overflow pathway is due to cell growth in the medium containing excess glucose; it enables the cell to generate ATP without utilizing the cytochrome system. In Bacillus, CcpA activates expression of genes required for acetate synthesis. Compared with neutraphilic bacteria, alkaliphiles survive in a much higher $\mathrm{pH}$ environment. However, it remains to be determined whether the two kinds of bacteria follow a similar metabolic pathway for different carbon sources, as well as protein expression of alkaliphilic bacteria under different carbon source conditions.

Alkaliphilic Bacillus sp. N16-5 was previously isolated from sediment of Wudunur Soda Lake in Inner Mongolia, China [21]; it is a facultative anaerobic, gram-positive bacterium with peritrichous flagella and grows well over a $\mathrm{pH}$ range of 8.5-11.5, and is optimal at $\mathrm{pH} 10$. The $\mathrm{NaCl}$ concentration growth range is $0 \%-15 \%$, with an optimal $\mathrm{NaCl}$ concentration of $8 \%$, and the bacteria produce and secrete numerous hydrolytic enzymes that enable the cells to degrade different substrates and grow on a wide variety of nutrient sources. This makes Bacillus sp. N16-5 an interesting organism for industrial biorefinery. The draft genome sequence of Bacillus sp. N16-5 provides a basis for proteomic studies of the bacterium, and to fully exploit its potential for metabolic engineering, a deeper understanding of the central energy and precursor generating pathways is neces- sary [22]. In the present study, a 2-DE map was created to provide a global overview of protein expression under a glucose-positive condition. This map was then used to measure the relative abundance of proteins involved in sugar metabolism for the purpose of identifying cellular responses to different carbon sources. To the best of our knowledge, this study was the first to report global proteomic profiles in response to different carbohydrates in alkaliphilic microorganisms, which could provide a useful resource for further studying the physiology of alkaliphiles.

\section{Materials and methods}

\subsection{Bacterial strain and growth condition}

Bacillus sp. N16-5 (CGMCC No. 0369) was previously isolated from sediment of Wudunur Soda Lake in Inner Mongolia, China [21]. Bacillus sp. N16-5 was grown in modified alkaline Horikoshi-II medium [23] under aerobic conditions at $37^{\circ} \mathrm{C}$ in round-bottom flasks, which included $0.5 \%(\mathrm{w} / \mathrm{v})$ sole carbon sources (glucose, mannose, galactose, arabinose, and xylose). The growth curve was determined in triplicate. For each growth condition, bacterial cell samples were harvested at the mid-exponential growth phase by centrifugation at $8000 \times g$ at $4{ }^{\circ} \mathrm{C}$ for $20 \mathrm{~min}$ and washed three times with Tris- $\mathrm{HCl}(\mathrm{pH} \mathrm{7.8)}$ and then stored at $-80^{\circ} \mathrm{C}$ until use.

\subsection{Preparation of cytoplasmic proteins}

Cell pellets were resuspended in Tris- $\mathrm{HCl}(\mathrm{pH}$ 7.8) buffer with $1 \mathrm{mmol} \mathrm{L}{ }^{-1} \mathrm{PMSF}$ and disrupted by sonication for 30 $\min$ on ice ( $300 \mathrm{~W}, 3 \mathrm{~s}$ vs. $5 \mathrm{~s}$ break). The suspension was centrifuged at $12000 \times \mathrm{g}$ for $20 \mathrm{~min}$ at $4{ }^{\circ} \mathrm{C}$ to remove unbroken cells and large cellular debris. The supernatant was precipitated by incubating with $10 \%$ trichloroacetic acid and acetone cooled to $-20^{\circ} \mathrm{C}$ for $30 \mathrm{~min}$. The insoluble pellets were washed three times with cold acetone, vacuum-dehydrated, and stored at $-80^{\circ} \mathrm{C}$ until further use. For $2 \mathrm{D}$ gel electrophoresis, protein pellets were resuspended in lysis buffer $\left(7 \mathrm{~mol} \mathrm{~L}^{-1}\right.$ urea, $2 \mathrm{~mol} \mathrm{~L}{ }^{-1}$ thiourea, $50 \mathrm{mmol} \mathrm{L}^{-1}$ Tris-HCl pH 8.0, 2\% (w/v) ASB-14, $10 \mathrm{mmol} \mathrm{L}^{-1}$ DTT and 2 mmol L ${ }^{-1}$ EDTA, 0.5\% (v/v) Pharmalytes 4-7 (Amersham Pharmacia Biosciences)). Protein concentrations were measured using the Bradford method with a Bio-Rad protein assay kit. Bovine serum albumin served as the standard. Two independent experiments were performed for each condition.

\subsection{D-PAGE proteomic analysis}

Cytoplasmic protein aliquots $(100 \mu \mathrm{g}$ protein) were mixed with rehydration solution $\left(8 \mathrm{~mol} \mathrm{~L}^{-1}\right.$ urea, 4\% CHAPS, 65 mmol L ${ }^{-1}$ DTT, $0.5 \%(\mathrm{v} / \mathrm{v})$ Pharmalytes) at a final volume 
of $450 \mu \mathrm{L}$. The aliquots were evenly loaded onto IPG strips (linear; $24 \mathrm{~cm}$ in length; $\mathrm{pH} 4-7$; GE Healthcare, USA) by overnight rehydration. Isoelectric focusing (IEF) was performed in five steps $(200 \mathrm{~V}$ for $1 \mathrm{~h}, 500 \mathrm{~V}$ for $1 \mathrm{~h}$, and 1 $000 \mathrm{~V}$ for $1 \mathrm{~h}$, followed by a gradient switch of 1000-10000 $\mathrm{V}$ for $1 \mathrm{~h}$ and $10000 \mathrm{~V}$, continuing until the total volt-hours reached $80 \mathrm{kVh}$ ) at $20^{\circ} \mathrm{C}$ following manufacture instructions (GE Healthcare). Prior to the second dimension, the IPG strips were equilibrated with two equilibration steps. The strips were first incubated for $15 \mathrm{~min}$ in a solution containing $6 \mathrm{~mol} \mathrm{~L}^{-1}$ urea, $2 \%(\mathrm{w} / \mathrm{v}) \mathrm{SDS}, 50 \mathrm{mmol} \mathrm{L}{ }^{-1}$ Tris- $\mathrm{HCl}$ ( $\mathrm{pH} 8.8$ ), 30\% (w/v) glycerol, and 1.0\% (w/v) DTT. Subsequently, the solutions were discarded, and the strips were incubated in a solution containing $6 \mathrm{~mol} \mathrm{~L}^{-1}$ urea, $2 \%(\mathrm{w} / \mathrm{v})$ SDS, $50 \mathrm{mmol} \mathrm{L}^{-1}$ Tris-HCl ( $\mathrm{pH} \mathrm{8.8),} \mathrm{30 \%} \mathrm{(w/v)} \mathrm{glycerol,}$ and $2.5 \%(\mathrm{w} / \mathrm{v})$ iodoacetamide. Following equilibration, the strips were placed on $12.5 \%$ SDS-PAGE gels using the Ettan DALTsix apparatus (GE Healthcare). Electrophoresis was performed using a constant current of $10 \mathrm{~mA} / \mathrm{gel}$ for $30 \mathrm{~min}$. Subsequently, the current was increased to $25 \mathrm{~mA} / \mathrm{gel}$ for another $7 \mathrm{~h}$. The gels were visualized by silver staining. Each sample set was performed in triplicate.

\subsection{Gel image analysis}

2D-PAGE protein patterns were recorded as digitized images with Labscan3 (GE Healthcare). Profile analyses and statistical analyses of protein spot data were performed using software properties supplied with the ImageMaster 2D Platinum 6.0 (GE Healthcare). To correct for differences in sample loading or staining intensity between gels, the 'total quantity in valid spot' normalization method was used. Duplicated gels from the same sample were grouped together using the 'replicate groups' function, which allows the average quantity of protein spots to be determined. The relative volume of each protein spot was the fraction of that spot volume to the total volume of all spots in a gel. The fold was calculated from the averages of relative volumes in two biological samples. Significant changes in protein levels were defined by at least a two-fold difference.

\subsection{In-gel digestion}

Separated protein spots were picked with a 1.5-mm Spot Picker and transferred to $1.5-\mathrm{mL}$ tubes. Gel pieces were destained by incubating in $30 \mathrm{mmol} \mathrm{L} \mathrm{L}^{-1}$ potassium ferricyanide and $65 \mathrm{mmol} \mathrm{L}^{-1}$ sodium thiosulfate and were washed in Milli-Q water until they were colorless and transparent. After drying with a SpeedVac concentrator, gel pieces were incubated for $1 \mathrm{~h}$ at $56^{\circ} \mathrm{C}$ in $20 \mu \mathrm{L}$ of $10 \mathrm{mmol} \mathrm{L}^{-1} \mathrm{DTT}$ plus $25 \mathrm{mmol} \mathrm{L}{ }^{-1}$ ammonium bicarbonate for reduction, and were subsequently alkylated for $30 \mathrm{~min}$ at room temperature in $20 \mu \mathrm{L}$ of $100 \mathrm{mmol} \mathrm{L}^{-1}$ iodoacetamide plus $50 \mathrm{mmol} \mathrm{L}^{-1}$ ammonium bicarbonate in the dark. The gel pieces were washed with $\mathrm{ACN} / 25 \mathrm{mmol} \mathrm{L}{ }^{-1} \mathrm{NH}_{4} \mathrm{HCO}_{3}(1: 1)$ and dehy- drated with ACN and dried in a SpeedVac concentrator. Dried gel pieces were rehydrated in $4-7 \mu \mathrm{L}$ of trypsin solution $\left(10 \mathrm{mg} \mathrm{mL}^{-1}\right.$; proteomics grade, Sigma, in $25 \mathrm{mmol} \mathrm{L}^{-1}$ ammonium bicarbonate) at $4^{\circ} \mathrm{C}$ for at least $40 \mathrm{~min}$. The gel pieces were then covered with $25 \mathrm{mmol} \mathrm{L}^{-1}$ ammonium bicarbonate and incubated at $37^{\circ} \mathrm{C}$ for $12-16 \mathrm{~h}$. Peptides were subsequently extracted twice with $50 \mu \mathrm{L} 50 \%$ ACN/5\% TFA, and the extracted solutions were combined and dried using a SpeedVac concentrator.

\subsection{Protein identification}

For MALDI-TOF-MS identification, the protein spots of interest were excised, and in-gel protein digestions were performed as previously described [24]. Dried tryptic peptide mixtures were dissolved in $0.7 \mu \mathrm{L}$ saturated CHCA matrix solution (5 mg mL $\mathrm{mL}^{-1} \mathrm{CHCA}$ in $50 \% \mathrm{ACN} / 0.1 \% \mathrm{TFA}$ ) and spotted onto a freshly cleaned target plate. After air drying, the crystallized spots were processed with a MALDI-TOF-MS mass spectrometer (4700 Proteomics Analyzer, Applied Biosystems, USA). All mass spectra were recorded in a reflector mode, with a mass range of 900-3700 Da using a 200-Hz laser at a repetition rate and wavelength of $355 \mathrm{~nm}$. The accelerated voltage was $2 \mathrm{kV}$. Conversion of time-of-flight (TOF) to mass (Da) for the monoisotopic ions $[\mathrm{M}+\mathrm{H}]^{+}$was based on calibration with a peptide standard kit (Applied Biosystems) containing des-Arg ${ }^{1}$-bradykinin $(\mathrm{m} / \mathrm{z}$ 904), angiotensin I $(\mathrm{m} / \mathrm{z}$ 1296), Glu ${ }^{1}$-fibrinopeptide B $(\mathrm{m} / \mathrm{z}, 1570)$, ACTH $(1-17, \mathrm{~m} / \mathrm{z}, 2093)$, ACTH (18-39, m/z 2465), and ACTH (7-38, m/z 3657). The resulting MS (PMF) and $\mathrm{MS}^{2}$ spectra were searched using MASCOT software incorporated in the Applied Biosystems GPS v3.5 Explorer against the protein sequence database of Bacillus sp. N16-5 (trypsin constraint of one missed cleavage and a static modification of $+57 \mathrm{Da}$ on Cysteine residue, as well as $+16 \mathrm{Da}$ on Methionine residue). All amino acid sequences of differential proteins were submitted to the PSORTb database to predict subcellular location [25]. In addition, proteins were grouped into categories according to functions by comparing to NCBI COG databases [26].

\subsection{Real-time PCR}

Total RNA in Bacillus sp. N16-5, which was cultured in different carbon sources, was extracted using the Trizol reagent kit (TaKaRa) according to manufacture instructions. The extraction was repeated from two independent cultures. Extracted RNA was dissolved in $50 \mu \mathrm{L}$ water. Genomic contamination in total RNA was carefully removed by DNase (Promega) treatment for $30 \mathrm{~min}$ at $37^{\circ} \mathrm{C}$. To obtain cDNA, the above preparation (500 ng RNA) was mixed with reagents provided in the PrimeScript ${ }^{\mathrm{TM}} \mathrm{RT}$ Reagent kit (TaKaRa). The mixture was incubated for $15 \mathrm{~min}$ at $37^{\circ} \mathrm{C}$, and the reaction was terminated by incubation at $70^{\circ} \mathrm{C}$ for 5 
s. The cDNA was mixed with reagents provided in the $\mathrm{SYBR}^{\circledR}$ Premix Ex Taq kit (TaKaRa) at a final volume of $20 \mu \mathrm{L}$. Quantification of PCR reactions was conducted in Mastercycler ${ }^{\circledR}$ ep realplex system with programmed parameters: $95^{\circ} \mathrm{C}$ for $15 \mathrm{~s}$ followed by 40 cycles of 2-stage temperature profile of $95^{\circ} \mathrm{C}$ for $5 \mathrm{~s}$ and $60^{\circ} \mathrm{C}$ for $35 \mathrm{~s}$. The melting curves for each PCR reaction were carefully analyzed to avoid non-specific amplifications of PCR products. Relative gene expression was calculated using the $2^{-\Delta \Delta \mathrm{Ct}}$ formula, which was normalized to 16s rRNA levels. Each sample was tested in triplicate.

\section{Results}

\subsection{Growth curves of Bacillus sp. N16-5 using different carbon sources}

Bacillus sp. N16-5 grew well in the media containing glucose, mannose, galactose, arabinose, and xylose as sole carbon sources, respectively. When cultured in the medium containing two of these carbon sources, the bacteria exhibited diauxic growth. The effectiveness of carbon sources could be ranked as glucose, galactose, mannose, arabinose, and xylose (data not shown). The growth curves of Bacillus sp. N16-5 with different carbon sources (Figure 1) show that it had different growth rates with different carbon sources. Strain N16-5 reached a mid-exponential growth phase after $10 \mathrm{~h}$ when grown on hexose (glucose, galactose, and mannose), compared with $12 \mathrm{~h}$ on pentose (arabinose and xylose). According to the growth curves, the cells were harvested during the mid-exponential growth phase.

\subsection{Comparative analyses of proteomes from Bacillus sp. N16-5 grown on various hexoses}

To identify proteins induced by different carbohydrates in Bacillus sp. N16-5, analysis of the cytoplasmic proteome was performed using 2-DE. The 2-DE map of the cytoplasmic proteome of glucose-cultured Bacillus sp. N16-5 cells was used as a reference map (Figure 2A) and compared with cytoplasmic proteomes of Bacillus sp. N16-5 grown on mannose and galactose. Differentially expressed protein spots were analyzed by MALDI-TOF-MS to obtain a peptide mass fingerprint (PMF). Proteins were identified by matching PMF of identified proteins with a local database established, based on the draft genome sequence of Bacillus sp. N16-5. Similar to the growth phenotype at mid-log phase, proteomic analysis of two hexose-cultured (mannose and galactose) cells showed similar protein patterns with glucose on 2-DE gels. However, results demonstrated that mannose as the sole carbon source resulted in the identification of 22 differentially expressed protein spots (Figure 2B). Of these differentially expressed proteins, eight were down-regulated, seven were up-regulated, three were newly synthesized, and four were not expressed. With galactose as the sole carbon source, 34 differentially expressed proteins were identified (Figure 2C). Among them, 10 were downregulated, 16 were up-regulated, four were newly synthesized, and 16 were not expressed. Most differentially expressed proteins were enzymes involved in carbohydrate metabolism, amino acid transport, and metabolism, as well as energy production and conversion. Several differentially expressed proteins (spot 7, 24, 26, 37, 41, and 50) exhibited similar trends. Table 1 summarizes identification results of
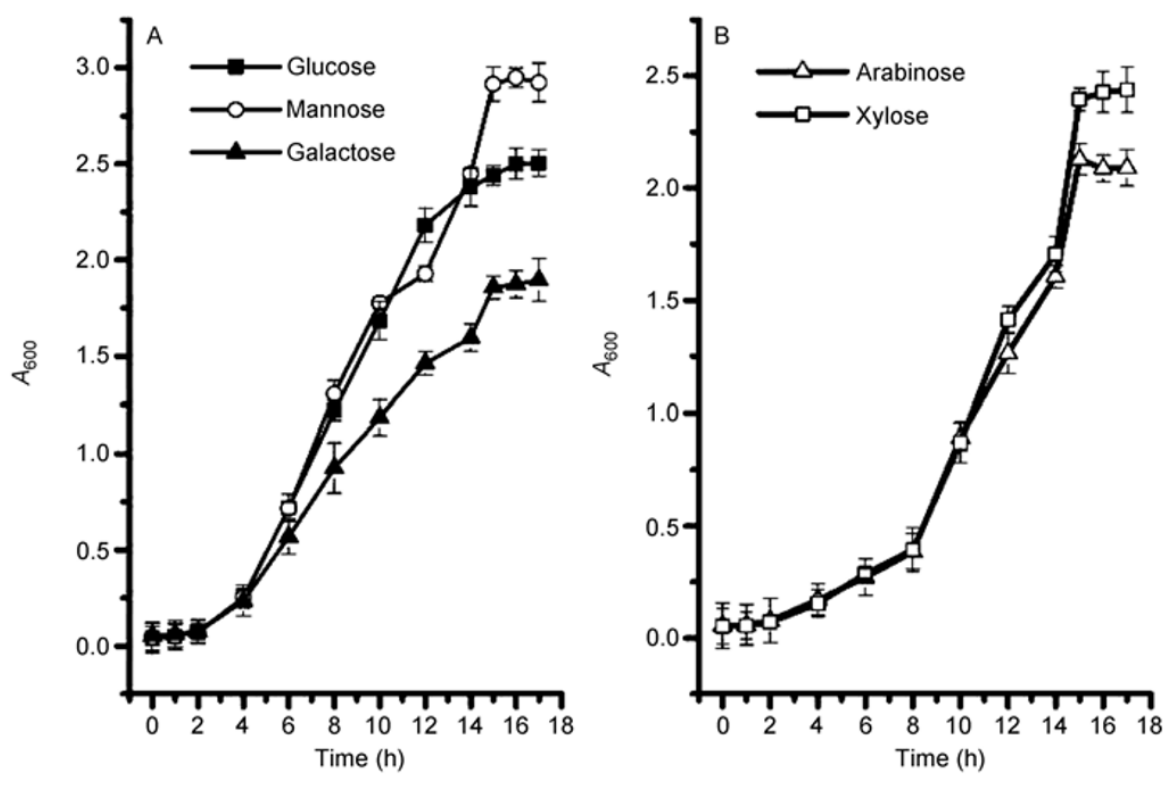

Figure 1 Growth curves of Bacillus sp. N16-5 with different carbon sources. 

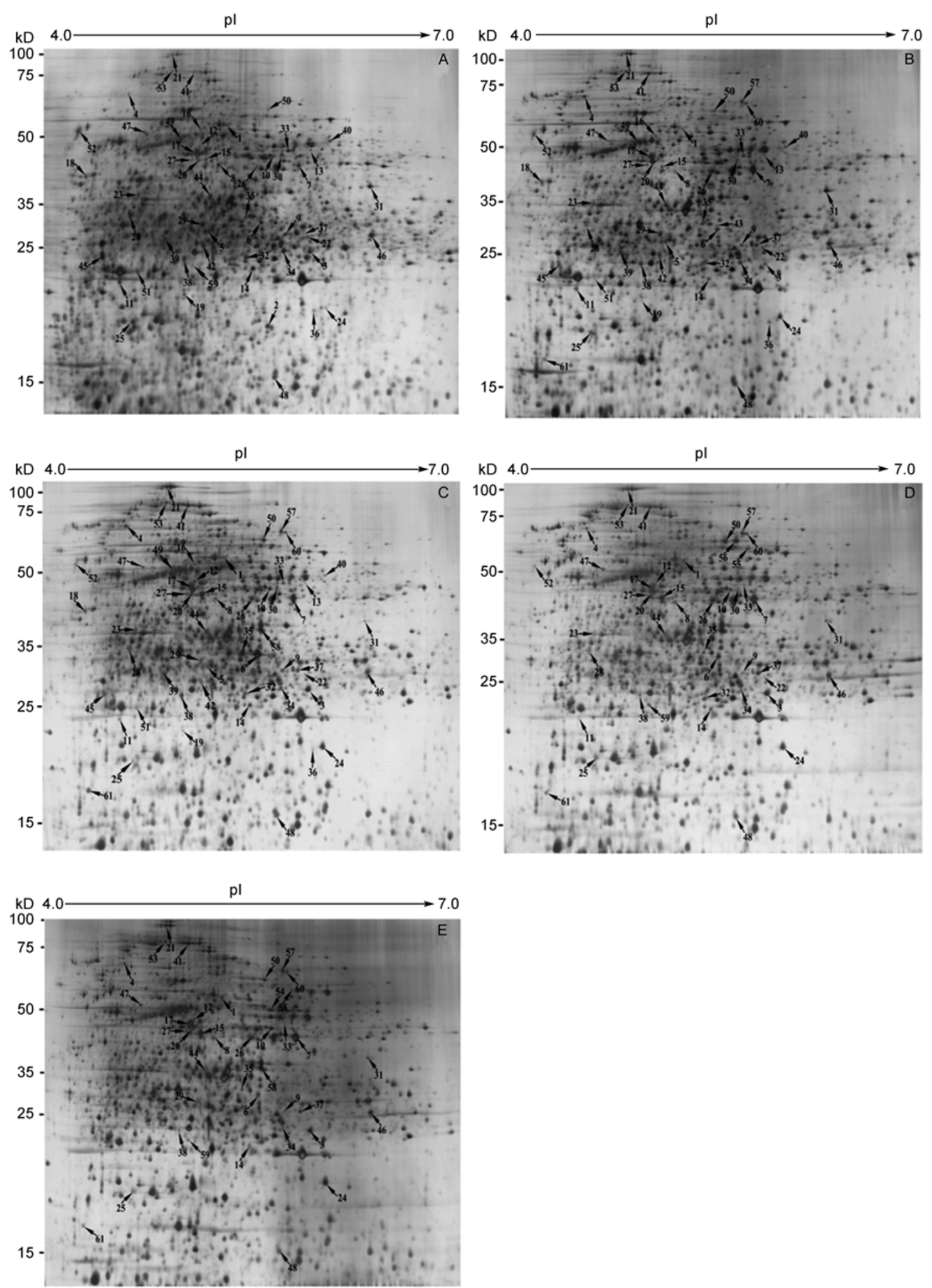

Figure 2 2-DE maps of cytoplasmic Bacillus sp. N16-5 proteins grown on hexose and pentose. A, Glucose; B, mannose; C, galactose; D, arabinose; E, xylose. Soluble proteins from crude cellular lysate $(100 \mu \mathrm{g})$ were separated on IPG strips $(24 \mathrm{~cm}$ in length, pH 4-7), followed by $12.5 \%$ SDS-PAGE gels. Proteins in the 2-DE gels were visualized by silver nitrate staining. 
Table 1 Relative expression changes and subcellular localization of proteins identified in the cytoplasmic fraction ${ }^{\text {a) }}$

\begin{tabular}{|c|c|c|c|c|c|c|c|c|}
\hline \multirow{2}{*}{ Spot No. } & \multirow{2}{*}{ Homologous function } & \multirow{2}{*}{$\begin{array}{l}\text { Sequence cov- } \\
\text { erage }(\%)\end{array}$} & \multirow{2}{*}{ Score } & \multirow{2}{*}{ Fraction } & \multicolumn{4}{|c|}{ Fold change (vs. glucose) } \\
\hline & & & & & Man & Gal & Ara & Xyl \\
\hline 1 & ADP-ribose diphosphatase & 43 & 197 & $\mathrm{C}$ & 1.29 & 2.36 & 2.80 & 2.61 \\
\hline 2 & PTS fructose-specific IIC component-like protein & $\begin{array}{l}27 \\
14\end{array}$ & $\begin{array}{l}43 \\
47\end{array}$ & M & - & - & - & - \\
\hline 3 & Transaldolase & 47 & 372 & $\mathrm{C}$ & 0.43 & 2.14 & 2.23 & 1.94 \\
\hline 4 & PTS system, enzyme I & 10 & 135 & $\mathrm{C}$ & 1.86 & 2.54 & 1.59 & 1.66 \\
\hline 5 & 6-phosphofructokinase & 14 & 97 & $\mathrm{C}$ & 1.24 & 0.69 & - & - \\
\hline 6 & Fructose-bisphosphate aldolase & 64 & 565 & $\mathrm{C}$ & 0.80 & 4.61 & 1.30 & 1.01 \\
\hline 7 & Glyceraldehyde-3-phosphate dehydrogenase & 17 & 55 & $\mathrm{C}$ & 3.04 & 3.08 & 3.55 & 5.15 \\
\hline 8 & Mannose-6-phosphate isomerase & 30 & 156 & $\mathrm{C}$ & 0.37 & 0.45 & 0.56 & 0.57 \\
\hline 9 & $\mathrm{NAD}(+)$ kinase & 14 & 67 & $\mathrm{C}$ & 0.53 & 0.58 & 0.40 & 0.30 \\
\hline 10 & Hypothetical protein & 20 & 95 & $\mathrm{C}$ & - & 2.07 & 1.40 & 3.59 \\
\hline 11 & 5'-nucleotidase & 34 & 224 & $\mathrm{C}$ & 0.91 & 0.38 & 0.17 & - \\
\hline 12 & Isocitrate dehydrogenase & 13 & 88 & $\mathrm{C}$ & 4.08 & 4.17 & 4.55 & 4.57 \\
\hline 13 & Acetate kinase & 12 & 52 & $\mathrm{C}$ & 0.93 & 0.69 & - & - \\
\hline 14 & Malate dehydrogenase & 15 & 191 & $\mathrm{C}$ & 0.44 & 0.71 & 0.47 & 0.39 \\
\hline 15 & Succinate--CoA ligase & 30 & 410 & $\mathrm{C}$ & 1.05 & 5.90 & 5.93 & 6.86 \\
\hline 16 & 2-oxoglutarate dehydrogenase & 19 & 171 & $\mathrm{C}$ & 0.82 & 0.68 & - & - \\
\hline 17 & Pyruvate dehydrogenase & 34 & 247 & $\mathrm{C}$ & 0.76 & 0.52 & 0.55 & 1.03 \\
\hline 18 & Dihydrolipoyllysine-residue transferase & 11 & 154 & $\mathrm{C}$ & 0.91 & 0.63 & - & - \\
\hline 19 & Sigma-70 region 2 domain protein & 18 & 138 & $\mathrm{C}$ & 0.18 & 0.29 & - & - \\
\hline 20 & NADH-dependent butanol dehydrogenase & 27 & 291 & $\mathrm{C}$ & 0.71 & 0.98 & 1.05 & 1.48 \\
\hline 21 & Cytoplasmic chaperone TorD family protein & 16 & 473 & $\mathrm{C}$ & 0.84 & 1.13 & 2.08 & 1.20 \\
\hline 22 & Metal dependent phosphohydrolase & 12 & 54 & $\mathrm{C}$ & 0.59 & 0.56 & 0.21 & - \\
\hline 23 & Peptidyl-tRNA hydrolase & 19 & 99 & $\mathrm{C}$ & 1.76 & 0.70 & 0.28 & - \\
\hline 24 & tRNA pseudouridine synthase A & 71 & 359 & $\mathrm{C}$ & 17.0 & 18.7 & 22.3 & 25.2 \\
\hline 25 & GreA/GreB family elongation factor & 61 & 292 & $\mathrm{C}$ & 0.70 & 0.32 & 0.10 & 0.13 \\
\hline 26 & Catabolite control protein A/ccpA & 19 & 276 & $\mathrm{C}$ & 7.03 & 6.83 & 14.3 & 13.5 \\
\hline 27 & Indole-3-glycerol phosphate synthase & 10 & 85 & $\mathrm{C}$ & 1.58 & 2.04 & 2.34 & 2.76 \\
\hline 28 & Glutamate--ammonia ligase & 15 & 78 & $\mathrm{C}$ & 0.47 & 0.57 & 0.39 & 0.12 \\
\hline 29 & $\begin{array}{l}\text { Protein of unknown function DUF294, nucleoti- } \\
\text { dyltransferase putative }\end{array}$ & 32 & 63 & $\mathrm{C}$ & 0.87 & 0.36 & - & 0.30 \\
\hline 30 & DnaQ family exonuclease/DinG family helicase & 13 & 85 & $\mathrm{U}$ & 1.03 & 0.85 & 0.60 & - \\
\hline 31 & 1-phosphofructokinase & 31 & 70 & $\mathrm{C}$ & 1.12 & 0.12 & 0.16 & 0.20 \\
\hline 32 & MIP family channel protein & 42 & 124 & $\mathrm{C}$ & 0.56 & 0.63 & 0.46 & - \\
\hline 33 & Putative transaldolase & 28 & 260 & $\mathrm{C}$ & 0.60 & 0.49 & 0.22 & 0.19 \\
\hline 34 & Putative transaldolase & 15 & 104 & $\mathrm{C}$ & 0.57 & 0.65 & 0.47 & 0.26 \\
\hline 35 & Putative transaldolase & 11 & 47 & $\mathrm{C}$ & 1.49 & 6.80 & 1.33 & 1.27 \\
\hline 36 & D-3-phosphoglycerate dehydrogenase & 11 & 69 & $\mathrm{C}$ & 0.67 & 0.23 & - & - \\
\hline 37 & Glycoside hydrolase, family 43 & 31 & 174 & $\mathrm{C}$ & 8.55 & 14.9 & 17.3 & 13.2 \\
\hline 38 & Flavoprotein WrbA & 45 & 328 & $\mathrm{C}$ & 0.96 & 1.32 & 0.49 & 0.23 \\
\hline 39 & Hypothetical protein $\mathrm{BH} 2155$ & 50 & 223 & $\mathrm{U}$ & 1.27 & 0.34 & - & - \\
\hline 40 & Ribosomal protein L24 & 54 & 69 & $\mathrm{C}$ & 0.69 & 0.37 & - & - \\
\hline 41 & Translation elongation factors & 7 & 351 & $\mathrm{C}$ & 9.02 & 14.2 & 17.6 & 13.9 \\
\hline 42 & $\begin{array}{c}\text { Aspartyl/glutamyl-tRNA(Asn/Gln) amidotrans- } \\
\text { ferase subunit C }\end{array}$ & 37 & 45 & $\mathrm{C}$ & 0.73 & 0.61 & - & - \\
\hline 43 & Methyltransferase small & 51 & 49 & $\mathrm{C}$ & 0.73 & - & - & - \\
\hline 44 & Flagellar biosynthetic protein & 22 & 62 & $\mathrm{C}$ & 0.82 & 0.71 & 0.59 & 0.84 \\
\hline 45 & Elongation factor $\mathrm{Tu}$ & 30 & 179 & $\mathrm{C}$ & 0.36 & 0.32 & - & - \\
\hline 46 & Enoyl-(acyl carrier protein) reductase & 31 & 121 & $\mathrm{C}$ & 0.95 & 0.86 & 0.85 & 0.77 \\
\hline 47 & Peroxidase/catalase catalase & 17 & 394 & $\mathrm{U}$ & 0.26 & 1.49 & 2.78 & 1.63 \\
\hline 48 & Superoxide dismutase & 17 & 87 & $\mathrm{E}$ & 0.85 & 0.86 & 1.06 & 1.04 \\
\hline 49 & Diguanylate cyclase/phosphodiesterase & 35 & 337 & $\mathrm{C}$ & 0.78 & - & - & - \\
\hline 50 & Guanine deaminase & 32 & 524 & $\mathrm{C}$ & 5.21 & 10.2 & 13.2 & 7.59 \\
\hline 51 & 2-cys peroxiredoxin & 15 & 63 & $\mathrm{C}$ & 0.07 & 0.93 & - & - \\
\hline 52 & Trigger factor & 15 & 116 & $\mathrm{C}$ & 1.27 & 0.65 & 0.29 & - \\
\hline
\end{tabular}




\begin{tabular}{|c|c|c|c|c|c|c|c|c|}
\hline \multirow{2}{*}{ Spot No. } & \multirow{2}{*}{ Homologous function } & \multirow{2}{*}{$\begin{array}{l}\text { Sequence cov- } \\
\text { erage }(\%)\end{array}$} & \multirow{2}{*}{ Score } & \multirow{2}{*}{ Fraction } & \multicolumn{4}{|c|}{ Fold change (vs. glucose) } \\
\hline & & & & & Man & Gal & Ara & Xyl \\
\hline 53 & $\mathrm{ABC}$ transporter & 3 & 63 & $\mathrm{C}$ & 0.90 & 3.97 & 4.31 & 2.57 \\
\hline 54 & Xylose isomerase & 22 & 149 & $\mathrm{C}$ & & & & $0.15^{*}$ \\
\hline 55 & $\mathrm{~L}$-arabinose isomerase & 8 & 74 & $\mathrm{C}$ & & & $0.02^{*}$ & \\
\hline 56 & L-ribulokinase & 23 & 290 & $\mathrm{C}$ & & & $0.23^{*}$ & \\
\hline 57 & Catalase/peroxidase HPI & 10 & 79 & $\mathrm{C}$ & $0.06^{*}$ & $0.07^{*}$ & $0.1^{*}$ & $0.1^{*}$ \\
\hline 58 & Protein of unknown function & 34 & 190 & $\mathrm{U}$ & - & $0.30^{*}$ & $0.35^{*}$ & $0.33^{*}$ \\
\hline 59 & Amino-acid N-acetyltransferase & 9 & 75 & $\mathrm{C}$ & - & - & 3.02 & 1.82 \\
\hline 60 & Glutamate synthase small subunit & 11 & 48 & $\mathrm{C}$ & $0.04^{*}$ & $0.04^{*}$ & $0.06^{*}$ & $0.04^{*}$ \\
\hline 61 & General stress protein $17 \mathrm{M}$ & 49 & 262 & $\mathrm{U}$ & $0.07^{*}$ & $0.13^{*}$ & $0.05^{*}$ & $0.04^{*}$ \\
\hline
\end{tabular}

a) C, cytoplasm fraction; M, membrane fraction; E, extracellular; U, unknown; *, newly synthesized protein; Man, mannose; Gal, galactose; Ara, arabinose; Xyl, xylose. " $>2$ " and " $<0.5$ " represent increased protein and reduced protein levels, respectively.

differential enzymes involved in carbon source metabolism from all forms of hexose (mannose and galactose).

\subsection{Comparative analyses of Bacillus sp. N16-5 pro- teomes grown on different pentoses}

Cytoplasmic Bacillus sp. N16-5 proteomes grown on arabinose and xylose were compared to proteomes of cells grown on glucose (Figure 2A). Results demonstrate that when arabinose was used as the sole carbon source, 48 differentially expressed protein spots were identified (Figure 2D). Of these differentially expressed proteins, 13 were down-regulated, 15 were up-regulated, 14 were not expressed, and six were newly synthesized. Interestingly, of these newly synthesized spots, two were induced exclusively when grown on arabinose. When xylose was used as the sole carbon source, 46 differentially expressed proteins were identified (Figure 2E); 12 were up-regulated, 20 were down-regulated, five proteins were newly synthesized, and nine were not expressed. Of these newly synthesized proteins, one was unique when grown on xylose. Similarly, most differentially expressed proteins were involved in carbohydrate metabolism, amino acid transport, and metabolism, as well as energy production and conversion. Table 1 summarizes identification results from differential enzymes involved in carbon source metabolism from all forms of pentose (arabinose and xylose).

\subsection{Comparative analyses of proteomes of Bacillus sp. N16-5 grown on hexose and pentose}

Bacillus sp. N16-5 grew slowly on pentose compared with hexose-cultured conditions. When cytoplasmic proteomes from cells grown on hexose were compared to cells grown on pentose, 11 up-regulated proteins and 23 down-regulated proteins were identified. Among the down-regulated proteins, 11 were attenuated in a hexose condition, but not expressed in a pentose condition. These proteins were involved in carbohydrate metabolism (spot 5, 13, 16, and 36), ribosome synthesis (spot 40), amino acid metabolism (spot 18 and 42), transcription and translation process (spot 19 and 45), anti-oxide mechanism (spot 51), and an unknown function (spot 39). Among these proteins, 6-phosphofructokinase was shown to be directly involved in glycolysis. Acetate kinase (ackA) was responsible for the overflow pathway in cells cultured in the medium with excess glucose. In addition, three proteins (spot 54, 55, and 56), which were not detected under hexose conditions, were newly synthesized. MS identification showed that all were involved in pentose metabolism. In addition, some common changes were observed. The present results demonstrated that hexose and pentose exerted carbon catabolite repression (CCR), which was regulated by CcpA. However, mannose and galactose gave rise to six-fold CcpA abundance changes, and pentose resulted in $>13$-fold changes. tRNA pseudouridine synthase (spot 24) and guanine deaminase (spot 50) were up-regulated and play roles in post-translation modification of tRNA synthesis and GTP generation, respectively.

\subsection{Central carbon metabolic pathways in Bacillus sp. N16-5 grown on different carbon sources}

Genomic analysis indicated that Bacillus sp. N16-5 contained complete enzymes for the central carbon metabolic pathway. Comparative proteomic analysis revealed a total of 10 proteins in the glycolysis pathway (1-phosphofructokinase, 6-phosphofructokinase, fructose-bisphosphate aldolase, glyceraldehydes-3-phosphate dehydrogenase), pentose phosphate pathway (transaldolase, L-ribulokinase), and TCA cycle (isocitrate dehydrogenase, malate dehydrogenase, 2-oxoglutarate dehydrogenase, pyruvate dehydrogenase), which were identified from proteomes from five carbohydrates. Protein expression changes are listed in Table 1. Among the four proteins that were involved in the glycolysis pathway, 6-phosphofructokinase was reduced or absent with galactose, arabinose, and xylose, but increased with mannose. By contrast, fructose-bisphosphate aldolase was increased with galactose, arabinose, and xylose, but reduced with mannose. However, 1-phosphofructokinase was decreased with mannose, galactose, arabinose, and xylose. Glyceraldehyde-3-phosphate dehydrogenase expression increased with mannose, galactose, arabinose, and xylose, 
and TCA cycle enzyme levels were also changed. For example, malate dehydrogenase and pyruvate dehydrogenase levels decreased with all carbohydrates compared to glucose. In addition, isocitrate dehydrogenase levels increased with galactose, arabinose, and xylose, but decreased with mannose. In the pentose phosphate pathway, two enzymes were detected. Transaldolase expression increased with galactose, arabinose, and xylose, but decreased with mannose. However, L-ribulokinase was uniquely synthesized with arabinose. Some newly synthesized proteins, such as xylose isomerase, L-arabinose isomerase, and L-ribulokinase, were also detected with pentose. These proteins were involved in transformation prior to entering the central carbon metabolic pathway.

To summarize these results, the carbohydrates (metabolic intermediates) might enter central carbon metabolism at multiple steps: (i) For mannose, phosphorylated mannose was isomerized to fructose-6-phosphate by mannose-6phosphate isomerase and then incorporated into the glycolysis pathway. (ii) For arabinose and xylose, three unique proteins were detected under pentose, respectively. Xylose isomerase transformed from $\mathrm{D}$-xylose to $\mathrm{D}$-xylulose, and L-arabinose isomerase transformed from $\mathrm{L}$-arabinose to L-ribulose. In addition, L-ribulose was phosphorylated to
L-ribulose 5-phosphate by L-ribulokinase. These two substrates entered the pentose-phosphate pathway for further catabolism following transformation to xylulose.

\subsection{Validation of different proteins via real-time PCR}

The study was extended for further validation of proteomic observations with real-time PCR. Genes encoding the two proteins CcpA and AckA from 61 unique identifications were chosen for real-time PCR. Two pairs of PCR primers were designed according to corresponding gene sequences (Table 2). All PCR reactions generated amplified products as designed. Furthermore, as depicted in Figure 3, the cycle threshold values indicated that the mRNA differential tendency of two genes presented similar patterns to the proteomic determinations. These results suggested that transcription and translation were affected by different carbon sources.

\subsection{Functional analyses of differential Bacillus sp. N16-5 proteins grown on various carbon sources}

The use of subcellular localization prediction tools was necessary to allow researchers to identify proteins retained

Table 2 Primer sequences designed for real-time PCR

\begin{tabular}{ccc}
\hline Gene & Sense primer $\left(5^{\prime}-3^{\prime}\right)$ & Anti-sense primer $\left(5^{\prime}-3^{\prime}\right)$ \\
\hline$c c p A$ & ATCCGAATGTCAAACCAACTAC & TGGCAATATCTTCAATCCCTC \\
$a c k A$ & AGAGTGGTATGCTTGCTTTGTC & GATGTGA bicon size \\
$16 s$ r $N A$ & AACCGTGGAGGGTCCCAGTGCTAAT & 109 bp \\
\hline
\end{tabular}
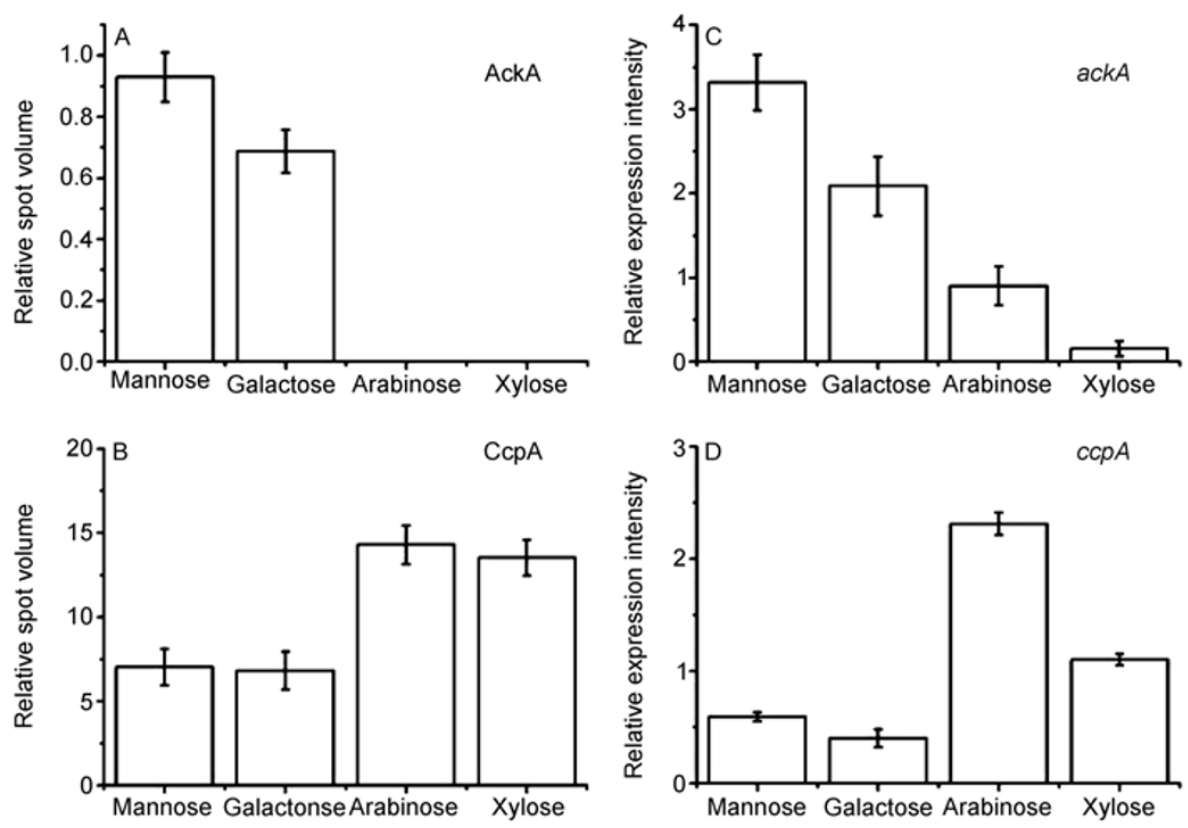

Figure 3 Comparison of differentially expressed genes under various carbon sources at mRNA and protein levels. A and B, Graphics showing two proteins at relative spot volumes, which were generated from 2-DE images with silver staining. C and D, Graphics showing the same two genes with relative expression intensity, which were produced by real-time PCR. 


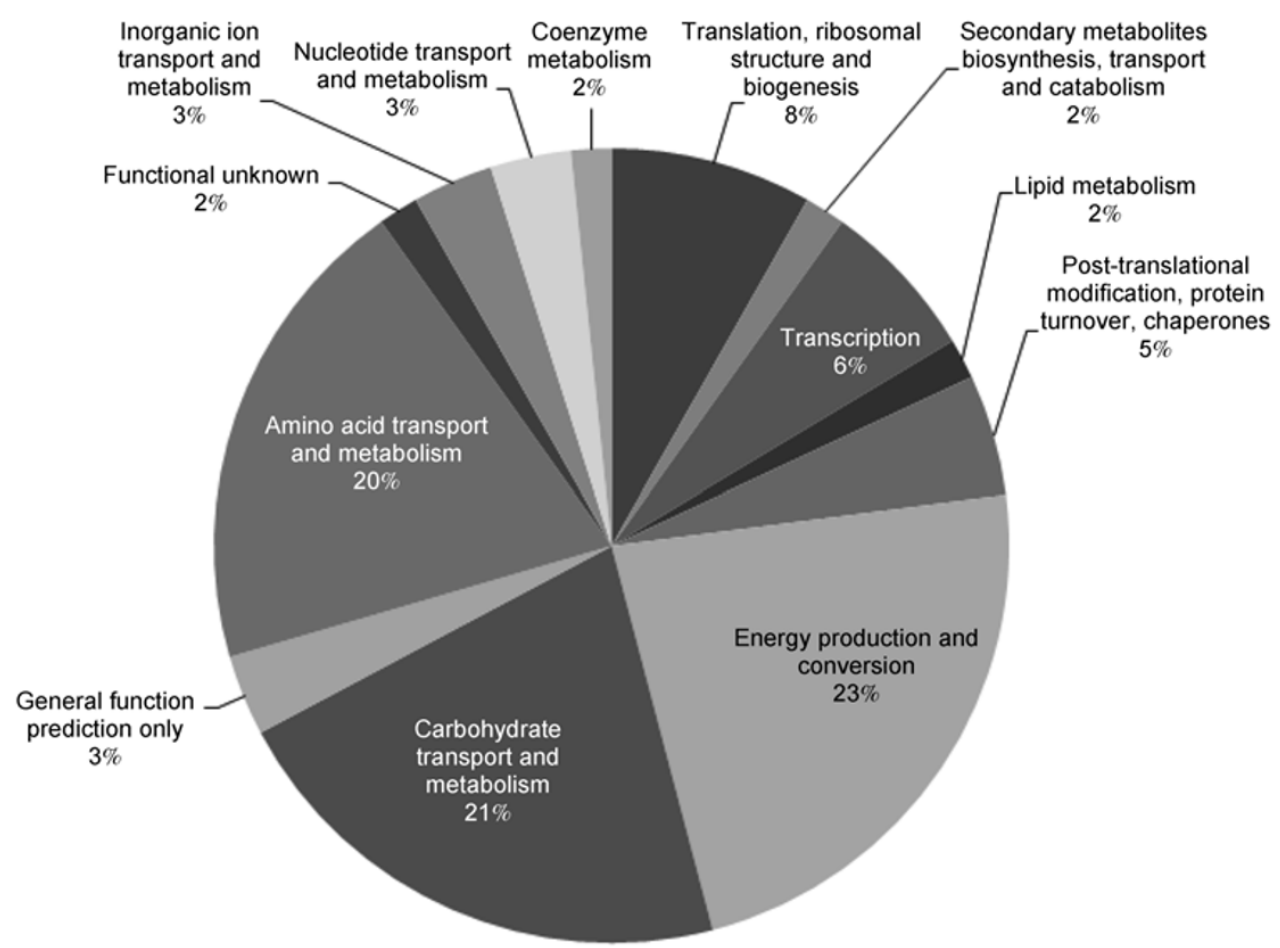

Figure 4 Functional analysis of cytoplasmic differential proteins of Bacillus sp. N16-5. The differential proteins were grouped into categories according to functions from NCBI COG databases.

and exported from cells [27]. In the current study, PSORTb was utilized to predict cellular locations of identified proteins. The differential Bacillus sp. N16-5 proteins responding to various carbon sources in the cytoplasm fraction were broadly divided into nine functional groups according to results from the NCBI COG database (Figure 4): (i) translation, ribosomal structure, and biogenesis, (ii) transcription, (iii) post-translational modification, protein turnover, and chaperones, (iv) energy production and conversion, (v) general function prediction only, (vi) metabolism, (vii) defense mechanisms, (viii) signal transduction mechanisms, and (ix) cell envelope biogenesis and outer membrane. Results indicated that differential strain N16-5 proteins in cytoplasmic regions were mainly involved in metabolism, as well as energy production and conversion.

\section{Discussion}

The utilization of highly sensitive 2-DE marked the dawn of the field of proteomics. Soon after its emergence, the technique was adapted for microbiology by the pioneering work of Neidhardt and van Bogelen for Escherichia coli [28,29]. 2-DE also provided the chance to gain deeper insight into alkaliphiles. Proteomic approaches using 2-DE could resolve hundreds of proteins in a single gel, and it was a powerful method for detecting novel enzymes or pathways, as well as discovering carbohydrate metabolism-related stimulons or regulons [30]. Therefore, proteomic information provided clues for a comprehensive understanding of bacterial cellular physiology when imposed by various environmental stimuli [17]. The prevalence of genomic information for Bacillus and related organisms allowed researchers to undertake a systems biology approach for understanding how certain bacteria adapt to specific environments [27].

Comparative proteomic analysis of Bacillus sp. N16-5 grown on hexose and pentose revealed that CcpA expression consistently increased by 6-13 folds on various carbohydrate compounds, compared with growth on glucose. Recent proteomic and transcriptome studies in Bacillus subtilis demonstrated that approximately 250 genes are subject to CcpA-dependent repression. The genes repressed by CcpA encoded enzymes are required for utilization of secondary carbon sources [31], which might be responsible for the disappearance of some proteins on various carbon sources, when compared with glucose conditions. In particular, there were larger expressional changes under pentose conditions, when compared with hexose, and some absent proteins were responsible for this growth. This could also result in slow growth under pentose conditions. In addition, in gramnegative $E$. coli, a large number of carbohydrates, in addition to glucose, exert CCR. However, CCR exerted by carbon sources other than glucose have not been systematically studied in B. subtilis [32]. Results from the present study showed that CcpA-mediated CCR was exerted by a variety of carbon sources in alkaliphilic Bacillus sp. N16-5, and pentose acted as a stronger effector than hexose in alkaliphilic Bacillus sp. N16-5. In addition, acetate kinase was 
repressed compared with high CcpA expression, when $B a$ cillus sp. N16-5 was grown in pentose conditions, which was not consistent with results from general Bacillus species [20].

By contrast, among the 10 proteins involved in central carbon metabolism, 6-phosphofructokinase was absent under pentose conditions. In addition, 6-phosphofructokinase is a key enzyme in glycolysis and correlates with formation of signal metabolites (fructose-1,6-biophosphate) for CCR. Therefore, it is possible that other alternative signal molecules activated CcpA in pentose conditions and could exist in alkaliphiles. Two other global regulators, TnrA and CodY, of Bacillus subtilis [33], which provide a top layer of general nutritional regulation that determines expression rate of central metabolism, were not detected in the present study. However, guanine deaminase, which is involved in formation of the effector molecule GTP, was detected and plays a role in regulation of cellular GTP and the guanylate nucleotide pool under certain circumstances [34]. The present results suggested that these might contribute to metabolism in pentose conditions, although there was no direct evidence to support this [35]. Some isomerases, which were involved in transformation of various hexose and pentose, were exclusively expressed under respective conditions. These isomerases isomerized carbohydrate and then entered the central carbon metabolism cycle. In addition, some proteins were observed in more than one spot (spot 33, 34, and 35), which could be explained by several factors: (i) Isoforms or post-translationally modified versions of the protein might be present in the cell; (ii) the protein was modified during protein extraction or 2-DE; (iii) the protein did not resolve well on the gel and, therefore, 'smeared' out over a large $\mathrm{pH}$ or mass range; (iv) the denaturizing conditions were not sufficient to completely break protein associations [22].

The complete enzyme system for central carbon metabolism of Bacillus sp. N16-5 enabled the metabolism of many carbohydrates, but CcpA-regulated CCR selected for the most easily utilized substrate, so that nutrients from a mixture of various carbon sources were efficient and achieved the fastest growth. Differential expression of CcpA, which was induced by hexose and pentose, exerted different repression activities on metabolic enzymes relative to the non-preferred carbon source. This phenomenon resulted in various growth rates. The present study investigated the effect of five carbon sources on the Bacillus sp. N16-5 proteome. Gene expression in these metabolic pathways was analyzed by measuring the relative abundance of proteins under various sugar-cultured conditions. The obtained proteomic data were interpreted according to central carbon metabolism, and expression levels of some key enzymes were altered in glycolysis and the TCA cycle. In addition, some hypothetical proteins with differential expression were detected, and these functions were not clear. Although the proteomic results suggested certain protein responses to various carbon sources, more details are needed to determine how these Bacillus sp. N16-5 molecules worked together to adapt to the external nutritional environment. In addition to measuring expression levels, transcriptome studies currently focus on activity modulation using microarray techniques. These studies could provide additional clues to better understand regulation of metabolism in alkaliphilic Bacillus sp. N16-5.

This work was supported by the National Basic Research Program of China, Ministry of Science and Technology of China (Grant Nos. 2007CB707801 and 2003CB716001) and the National High Technology Research and Development Program of China (Grant Nos. 2006AA020201 and 2007AA021306).

1 Horikoshi K. Alkaliphiles: Some applications of their products for biotechnology. Microbiol Mol Biol Rev, 1999, 63: 735-750

2 Rothschild L J, Mancinelli R L. Life in extreme environments. Nature, 2001, 409: 1092-1101

3 Padan E, Bibi E, Ito $\mathrm{M}$, et al. Alkaline $\mathrm{pH}$ homeostasis in bacteria: New insights. Biochim Biophys Acta, 2005, 1717: 67-88

4 Gomes J, Steiner W. The biocatalytic potential of extremophiles and extremozymes. Food Technol Biotech, 2004, 42: 223-235

5 Coolbear T, Daniel R M, Morgan H W. The enzymes from extreme thermophiles: Bacterial sources, thermostabilities and industrial relevance. Adv Biochem Eng Biotechnol, 1992, 45: 57-98

6 Adams M W, Perler F B, Kelly R M. Extremozymes: Expanding the limits of biocatalysis. Biotechnol (NY), 1995, 13: 662-668

7 Eisenberg H. Life in unusual environments: Progress in understanding the structure and function of enzymes from extreme halophilic bacteria. Arch Biochem Biophys, 1995, 318: 1-5

8 Ishida M, Yoshida M, Oshima T. Highly efficient production of enzymes of an extreme thermophile, Thermus thermophilus: A practical method to overexpress GC-rich genes in Escherichia coli. Extremophiles, 1997, 1: 157-162

9 Hough D W, Danson M J. Extremozymes. Curr Opin Chem Biol, 1999, 3: 39-46

10 Breithaupt $\mathrm{H}$. The hunt for living gold. The search for organisms in extreme environments yields useful enzymes for industry. EMBO Rep, 2001, 2: 968-971

11 Hoondal G S, Tiwari R P, Tewari R, et al. Microbial alkaline pectinases and their industrial applications: A review. Appl Microbiol Biotechnol, 2002, 59: 409-418

12 Marhuenda-Egea F C, Bonete M J. Extreme halophilic enzymes in organic solvents. Curr Opin Biotechnol, 2002, 13: 385-389

13 Schiraldi C, De Rosa M. The production of biocatalysts and biomolecules from extremophiles. Trends Biotechnol, 2002, 20: 515-521

14 Ferrer M, Golyshina O, Beloqui A, et al. Mining enzymes from extreme environments. Curr Opin Microbiol, 2007, 10: 207-214

15 Voigt B, Hoi le T, Jurgen B, et al. The glucose and nitrogen starvation response of Bacillus licheniformis. Proteomics, 2007, 7: 413-423

16 Gilmour R, Messner P, Guffanti A A, et al. Two-dimensional gel electrophoresis analyses of $\mathrm{pH}$-dependent protein expression in facultatively alkaliphilic Bacillus pseudofirmus OF4 lead to characterization of an S-layer protein with a role in alkaliphily. J Bacteriol, 2000, 182: 5969-5981

17 Hecker M, Volker U. Towards a comprehensive understanding of Bacillus subtilis cell physiology by physiological proteomics. Proteomics, 2004, 4: 3727-3750

18 Sonenshein A L. Control of key metabolic intersections in Bacillus subtilis. Nat Rev Microbiol, 2007, 5: 917-927

19 Gorke B, Stulke J. Carbon catabolite repression in bacteria: Many ways to make the most out of nutrients. Nat Rev Microbiol, 2008, 6: 613-624

20 Grundy F J, Waters D A, Allen S H, et al. Regulation of the Bacillus subtilis acetate kinase gene by CcpA. J Bacteriol, 1993, 175: 7348- 
7355

21 Ma Y T X, Zhou P, Wang D. Production and some properties of alkaline $\beta$-mannanase (in Chinese). Acta Microbiol Sin, 1991, 31: 443-448

22 Snijders A P, Walther J, Peter S, et al. Reconstruction of central carbon metabolism in Sulfolobus solfataricus using a two-dimensional gel electrophoresis map, stable isotope labelling and DNA microarray analysis. Proteomics, 2006, 6: 1518-1529

23 Horikoshi K. Production of alkaline enzymes by alkalophilic microorganisms. Agric Biol Chem, 1971, 36: 1407-1414

24 Shevchenko A, Wilm M, Vorm O, et al. Mass spectrometric sequencing of proteins silver-stained polyacrylamide gels. Anal Chem, 1996, 68: 850-858

25 Gardy J L, Laird M R, Chen F, et al. PSORTb v.2.0: Expanded prediction of bacterial protein subcellular localization and insights gained from comparative proteome analysis. Bioinformatics, 2005, 21: 617-623

26 Tatusov R L, Galperin M Y, Natale D A, et al. The COG database: A tool for genome-scale analysis of protein functions and evolution. Nucleic Acids Res, 2000, 28: 33-36

27 Graham R L, Pollock C E, O'Loughlin S N, et al. Multidimensional analysis of the insoluble sub-proteome of Oceanobacillus iheyensis HTE831, an alkaliphilic and halotolerant deep-sea bacterium isolated from the Iheya ridge. Proteomics, 2007, 7: 82-91

28 Pedersen S, Bloch P L, Reeh S, et al. Patterns of protein synthesis in E. coli: A catalog of the amount of 140 individual proteins at differ- ent growth rates. Cell, 1978, 14: 179-190

29 VanBogelen R A, Schiller E E, Thomas J D, et al. Diagnosis of cellular states of microbial organisms using proteomics. Electrophoresis, 1999, 20: 2149-2159

30 Qi S W, Chaudhry M T, Zhang Y, et al. Comparative proteomes of Corynebacterium glutamicum grown on aromatic compounds revealed novel proteins involved in aromatic degradation and a clear link between aromatic catabolism and gluconeogenesis via fructose-1,6-bisphosphatase. Proteomics, 2007, 7: 3775-3787

31 Wacker I, Ludwig H, Reif I, et al. The regulatory link between carbon and nitrogen metabolism in Bacillus subtilis: Regulation of the gltAB operon by the catabolite control protein CcpA. Microbiology, 2003, 149: 3001-3009

32 Singh K D, Schmalisch M H, Stulke J, et al. Carbon catabolite repression in Bacillus subtilis: Quantitative analysis of repression exerted by different carbon sources. J Bacteriol, 2008, 190: 7275-7284

33 Commichau F M, Gunka K, Landmann J J, et al. Glutamate metabolism in Bacillus subtilis: Gene expression and enzyme activities evolved to avoid futile cycles and to allow rapid responses to perturbations of the system. J Bacteriol, 2008, 190: 3557-3564

34 Maynes J T, Yuan R G, Snyder F F. Identification, expression, and characterization of Escherichia coli guanine deaminase. J Bacteriol, 2000, 182: 4658-4660

35 Petranovic D, Guedon E, Sperandio B, et al. Intracellular effectors regulating the activity of the Lactococcus lactis CodY pleiotropic transcription regulator. Mol Microbiol, 2004, 53: 613-621

Open Access This article is distributed under the terms of the Creative Commons Attribution License which permits any use, distribution, and reproduction in any medium, provided the original author(s) and source are credited. 